\title{
Studies on the Kinetics of Benzimidazolium Fluorochromate Oxidation of Pyridine-2-aldehyde in Aqueous Acetic Acid Medium
}

\author{
V SALEEM MALIK ${ }^{1}$, I VANNAMUTHU ${ }^{1,2}$, S SYED SHAFI $^{3}$ and S SHEIK MANSOOR ${ }^{1 *}$ \\ ${ }^{1}$ Department of Chemistry, C. Abdul Hakeem College (Autonomous), \\ Melvisharam - 632 509, Tamil Nadu, India \\ ${ }^{2}$ Department of Chemistry, Periyar Government Arts College, Cuddalore - 607 001, \\ Tamil Nadu, India \\ ${ }^{3}$ Department of Chemistry, Thiruvalluvar University, Serkadu, Vellore - 632 106, \\ Tamil Nadu, India \\ smansoors2000@yahoo.co.in
}

Received 23 November 2014 / Accepted 16 December 2014

\begin{abstract}
The oxidation of pyridine-2-aldehyde (2-PyA) by benzimidazolium fluorochromate (BIFC) has been studied in aqueous acetic acid medium. The oxidation leads to the formation of the pyridine-2-carboxylic acid. The reaction is first order with respect to [BIFC], [2-PyA] and $\left[\mathrm{H}^{+}\right]$and the reaction is catalyzed by hydrogen ions. The reaction mixture failed to induce the polymerization of added acrylonitrile. The reaction has been studied in different percentage of acetic acid-water mixture. The decrease in dielectric constant of the medium increases the rate of the reaction or low dielectric constant of the medium favours the reactivity. A suitable mechanism has been proposed.
\end{abstract}

Keywords: Pyridine-2-aldehyde, Benzimidazolium fluorochromate, Oxidation, Kinetics

\section{Introduction}

Aromatic and aliphatic aldehydes have many applications. Aromatic aldehydes act as a key chemical intermediate for the production of a variety of fine or special chemicals, such as pharmaceuticals, drugs, dyestuffs, pesticides and perfume composition ${ }^{1}$. Oxidation product of pyridine-2-aldehyde is pyridine-2-carboxylic acid (picolinic acid). It acts as a chelating agent of elements such as chromium, zinc, manganese, copper, iron, and molybdenum in the body. It is involved in phenylalanine, tryptophan, and alkaloids production and for the quantitative detection of calcium. This forms a complex with zinc, may facilitate the passage of zinc through the gastrointestinal wall and into the circulatory system. During the past decades, picolinic acid was found to have a number of biological functions. Commercially picolinic acid is used as an intermediate to produce pharmaceuticals (especially local anesthetics) and metal salts for the application of nutritional supplements. Picolinic acid 
chromium salt, a dietary supplement, may be used to study its potential as a modulator of glucose uptake and the activity of insulin. Picolinic acid also has protective and therapeutic effects against tumor through activation and subsequent enhancement of macrophagesmediated cytotoxicitiy and induces production of tumor-related proteins. Intriguingly, picolinic acid stimulates programmed cell death (PCD) in cancer cells and efficiently interrupts the progress of HIV in vitro ${ }^{2}$.

Kinetics of oxidation of benzaldehyde by various oxidizing agents have been well studied $^{3-10}$. A search of literature revealed that only few reports are available for kinetics of oxidation of heterocyclic aldehydes ${ }^{11-16}$.

Chromium compounds especially $\mathrm{Cr}(\mathrm{VI})$ reagents have been versatile reagents and capable of oxidizing almost all the oxidizable organic functional groups ${ }^{17}$. The development of newer $\mathrm{Cr}(\mathrm{VI})$ reagents for the oxidation of organic substrates continues to be of interest. In recent years, many such reagents have been developed and used to study the oxidation of various organic compounds ${ }^{18-24}$.

Benzimidazolium fluorochromate was reported to be a mild, stable and selective oxidant. A perusal of the literature showed that there seems to be a very few reports using BIFC ${ }^{25-30}$. Literature survey has also unveiled the fact that the study of oxidation of heterocyclic aldehyde like pyridine-2-aldehyde in aqueous acetic acid medium is lacking. As a part of our investigation on the mechanistic aspects of BIFC oxidations ${ }^{27-30}$, we report the results of BIFC oxidation of pyridine-2-aldehyde in aqueous acetic acid medium. The present investigation is an effort to probe into the kinetic and mechanistic aspects of BIFC oxidation of pyridine-2aldehyde in aqueous acetic acid medium in various solvent compositions and to determine thermodynamic parameters. A probable mechanism has been proposed.

\section{Experimental}

Benzimidazole and chromium trioxide were obtained from Fluka (Buchs, Switzerland). The heterocyclic aldehyde used was pyridine-2-aldehyde. BIFC was prepared by reported method $^{24}$ and its purity is checked by an iodometric method. Acetic acid was purified by standard method and the fraction distilling at $118^{\circ} \mathrm{C}$ was collected.

\section{Kinetic measurements}

The pseudo first-order conditions were attained by maintaining a large excess (X 15 or more) of heterocyclic aldehydes over BIFC. The solvent was $50 \%$ acetic acid $-50 \%$ water $(\mathrm{v} / \mathrm{v})$, unless specified otherwise. The reactions were followed, at constant temperatures $( \pm 0.01 \mathrm{~K})$, by monitoring the decrease in [BIFC] spectrophotometrically at $368 \mathrm{~nm}$ using UV-Vis spectrophotometer, Shimadzu UV-1800 model. The pseudo first-order rate constant $\mathrm{k}_{\text {obs }}$, was evaluated from the linear $(r=0.990$ to 0.999$)$ plots of $\log$ [BIFC] against time for up to $80 \%$ reaction. The second order rate constant $k_{2}$, was obtained from the relation $k_{2}=k_{o b s} /$ [Substrate].

\section{Data analysis}

Correlation analysis were carried out using Microcal origin (version 6) computer software. The goodness of the fit was discussed using the correlation coefficient ( $\mathrm{r}$ in the case of simple linear regression and $\mathrm{R}$ in the case of multiple linear regression) and standard deviation (SD)

\section{Product analysis}

Product analysis was carried out under kinetic conditions i.e., with excess of the substrate over BIFC. In a typical experiment, pyridine-2-aldehyde $(0.1 \mathrm{~mol})$, perchloric acid $(0.32 \mathrm{~mol})$ and BIFC $(0.01 \mathrm{~mol})$ were dissolved in acetic acid-water mixture $(50 \%-50 \%)$ and the solution 
was allowed to stand in the dark for about $48 \mathrm{~h}$ to ensure completion of the reaction. The reaction mixture was then evaporated and extracted with ether. The ether layer was washed with water many times. The ether layer was then kept on a water bath for the evaporation of ether and cooled in ice bath to obtain the product (m.p. $138-141{ }^{\circ} \mathrm{C}$; Lit. m.p. $139-142{ }^{\circ} \mathrm{C}$ ). The product was dissolved in benzene and a careful TLC analysis was done with picolinic acid (pyridine-2-carboxylic acid) as reference. Only one spot corresponding to picolinic acid was obtained. Formation of picolinic acid was further confirmed by mixing the product with pure picolinic acid and noting that there was no change in the melting point.

FT-IR spectra were obtained as KBr discs on Shimadzu spectrometer. ${ }^{1} \mathrm{H}$ NMR (500 $\mathrm{MHz})$ and ${ }^{13} \mathrm{C}$ NMR (125 MHz) spectra was obtained using Bruker DRX- 500 Avance at ambient temperature, using TMS as internal standard. Mass spectra were determined on a Varion - Saturn 2000 GC/MS instrument. Elemental analysis were measured by means of Perkin Elmer $2400 \mathrm{CHN}$ elemental analyzer flowchart.

\section{Pyridine-2-carboxylic acid (from pyridine-2-aldehyde)}

White crystalline solid; IR ( $\left.\mathrm{KBr}, \mathrm{cm}^{-1}\right)$ : 3034, 2878 (br, s, $\left.-\mathrm{OH}\right), 1698$ (s, C=O), 1477, 1036, 949, 768; ${ }^{1} \mathrm{H}$ NMR (500 MHz, DMSO- $\left.d_{6}\right) \delta: 11.2(\mathrm{~s}, 1 \mathrm{H}, \mathrm{COOH}), 8.92(\mathrm{~d}, 1 \mathrm{H}, \mathrm{CH})$, $8.22(\mathrm{~d}, 1 \mathrm{H}, \mathrm{CH}), 8.05(\mathrm{t}, 1 \mathrm{H}, \mathrm{CH}), 7.68(\mathrm{t}, 1 \mathrm{H}, \mathrm{CH}) \mathrm{ppm} ;{ }^{13} \mathrm{C}$ NMR $\left(125 \mathrm{MHz}\right.$, DMSO- $\left.d_{6}\right)$ $\delta: 124.8,126.6,136.9,147.9,149.3,172.2 \mathrm{ppm} ; \mathrm{MS}(\mathrm{ESI}): \mathrm{m} / z 124(\mathrm{M}+\mathrm{H})^{+}$. Anal. Calcd. for $\mathrm{C}_{6} \mathrm{H}_{5} \mathrm{NO}_{2}(\%)$ : C, 58.54; H, 4.09; N, 11.38. Found: C, 58.44; H, 4.02; N, 11.29.

\section{Stoichiometric studies}

The stoichiometric studies for the oxidation of 2-PyA by BIFC were carried out with oxidant in excess. The solvent composition $50 \%$ acetic acid $-50 \%$ water $(v / v)$ and $\left[\mathrm{H}^{+}\right]$were maintained as in the corresponding rate measurements. The temperature was maintained at $313 \mathrm{~K}$. Pyridine-2-aldehyde and BIFC were mixed in the ratio 1:4, 1:5, 1:6 and were allowed to react for $48 \mathrm{~h}$ at $313 \mathrm{~K}$. The concentration of unreacted BIFC was determined. $\Delta[\mathrm{BIFC}]$ was calculated. The stoichiometry was calculated from the ratio between [2-PyA] and [BIFC]. Stoichiometric analysis showed that $3 \mathrm{~mol}$ of aldehyde consumed $2 \mathrm{~mol}$ of BIFC in accordance with $\mathrm{Eq}$ (1) to give the corresponding carboxylic acid.

$$
\begin{aligned}
& 3 \mathrm{C}_{6} \mathrm{H}_{5} \mathrm{NO}_{2}+2 \mathrm{Cr}(\mathrm{VI})+3 \mathrm{H}_{2} \mathrm{O} \longrightarrow 3 \mathrm{C}_{6} \mathrm{H}_{5} \mathrm{NO}_{3}+2 \mathrm{Cr}(\mathrm{III})+6 \mathrm{H}^{+} \\
& \text {(Pyridine-2-aldehyde) }
\end{aligned}
$$

\section{Results and Discussion}

The oxidation of pyridine-2-aldehyde by BIFC has been conducted in $50 \%$ acetic acid and $50 \%$ water medium at $303 \mathrm{~K}$, under pseudo first order conditions and the result obtained were discussed in the following paragraphs.

\section{Effect of varying BIFC concentration}

The concentration of BIFC was varied in the range of $0.5 \times 10^{-3}$ to $2.5 \times 10^{-3} \mathrm{~mol} \mathrm{dm}^{-1}$ at constant [2-PyA $],\left[\mathrm{H}^{+}\right]$at $303 \mathrm{~K}$ and the rates were measured (Table 1). The near constancy in the value of $k_{o b s}$ irrespective of the concentration confirms the first order dependence on BIFC.

\section{Effect of varying heterocyclic aldehyde concentration}

The concentration of 2-PyA was varied in the range of $1.0 \times 10^{-2}$ to $3.0 \times 10^{-2} \mathrm{~mol} \mathrm{dm}^{-1}$ at $303 \mathrm{~K}$ and keeping all other reactant concentrations as constant and the rates were measured (Table 1). The rate of oxidation increased progressively on increasing the concentration of 2-PyA. The plot of $\log k_{\mathrm{obs}}$ versus $\log$ [2-PyA] gave the slope of 1.03 for 2-PyA (Figure 1). Under 
pseudo first-order conditions, the plot of of $k_{\mathrm{obs}}$ versus [2-PyA] is linear passing through origin (Figure 2). These results confirm the first-order nature of the reaction with respect to [2-PyA].

\section{Effect of varying perchloric acid concentration}

Perchloric acid has been used as a source of $\mathrm{H}^{+}$in reaction medium. The concentration of $\mathrm{H}^{+}$ was varied in the range 0.16 to $0.48 \mathrm{~mol} \mathrm{dm}^{-1}$ keeping all other reactant concentration as constant at $303 \mathrm{~K}$ and the rates were measured (Table 1). The acid catalysed nature of this oxidation is confirmed by an increase in the rate on the addition of $\mathrm{H}^{+}$. The plot of $\log k_{\mathrm{obs}}$ versus $\log \left[\mathrm{H}^{+}\right]$is a straight line with the slope of 1.03 for 2-PyA. Therefore, order with respect to $\mathrm{H}^{+}$is one for 2-PyA. BIFC may become protonated in the presence of acid and the protonated BIFC may function as an effective oxidant.

Table 1. Effect of variation of [2-PyA], $[\mathrm{BIFC}]$ and $\left[\mathrm{H}^{+}\right]$on the rate of the reaction at $303 \mathrm{~K}^{\mathrm{a}, \mathrm{b}}$

\begin{tabular}{ccccc}
\hline $\begin{array}{c}10^{3}[\mathrm{BIFC}], \\
\mathrm{mol} \mathrm{dm}^{-3}\end{array}$ & $\begin{array}{c}10^{2}[2-\mathrm{PyA}], \\
\mathrm{mol} \mathrm{dm}^{-3}\end{array}$ & {$\left[\mathrm{H}^{+}\right], \mathrm{mol} \mathrm{dm}^{-3}$} & $\begin{array}{c}10^{4} k_{1}{ }^{\mathrm{b}} \\
\mathrm{s}^{-1}\end{array}$ & $\begin{array}{c}10^{2} k_{2}{ }^{\mathrm{c}} \\
\mathrm{dm}^{3} \mathrm{~mol}^{-1} \mathrm{~s}^{-1}\end{array}$ \\
\hline 0.5 & 2.0 & 0.32 & 3.30 & 1.65 \\
1.0 & 2.0 & 0.32 & 3.34 & 1.67 \\
1.5 & 2.0 & 0.32 & 3.42 & 1.71 \\
2.0 & 2.0 & 0.32 & 3.38 & 1.69 \\
2.5 & 2.0 & 0.32 & 3.26 & 1.63 \\
1.0 & 1.0 & 0.32 & 1.56 & 1.56 \\
1.0 & 1.5 & 0.32 & 2.58 & 1.72 \\
1.0 & 2.5 & 0.32 & 4.05 & 1.62 \\
1.0 & 3.0 & 0.32 & 4.89 & 1.63 \\
1.0 & 2.0 & 0.16 & 1.70 & 0.11 \\
1.0 & 2.0 & 0.24 & 2.44 & 0.10 \\
1.0 & 2.0 & 0.40 & 4.22 & 0.11 \\
1.0 & 2.0 & 0.48 & 5.02 & 0.10 \\
\hline
\end{tabular}

${ }^{a}$ As determined by spectrophotometrically following the disappearance of Cr(VI) at $368 \mathrm{~nm}$; the error quoted in $k$ values is the 95\% confidence limit of 'Student $t$ test'. ${ }^{b}$ Estimated from pseudo first order plots over $80 \%$ reaction. ${ }^{c}$ Individual $k_{2}$ values estimated as $k_{1} /[2-P y A]$ or $k_{1} /\left[H^{+}\right]$Solvent Composition $=50 \% \mathrm{AcOH}-50 \% \mathrm{H}_{2} \mathrm{O}(\mathrm{v} / \mathrm{v})$

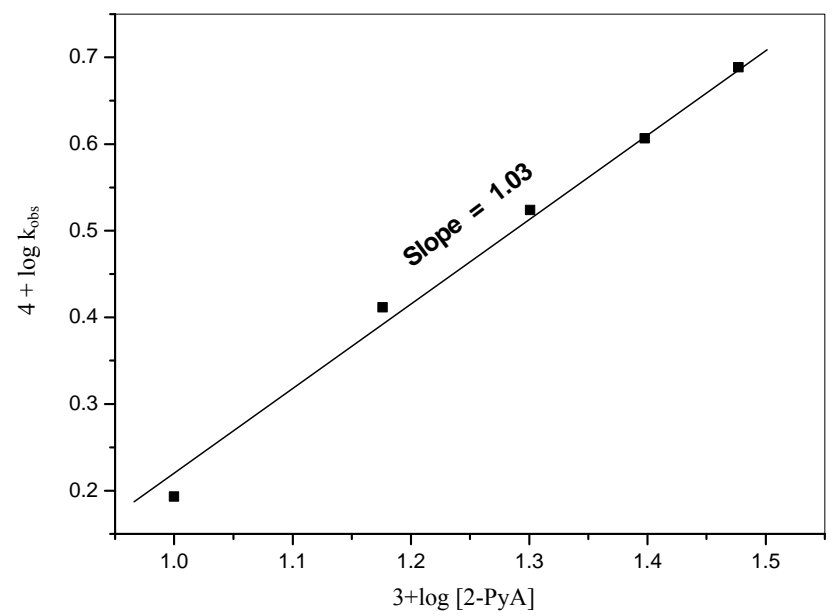

Figure 1. Order plot of pyridine-2-aldehyde for the oxidation of pyridine-2-aldehyde by BIFC 


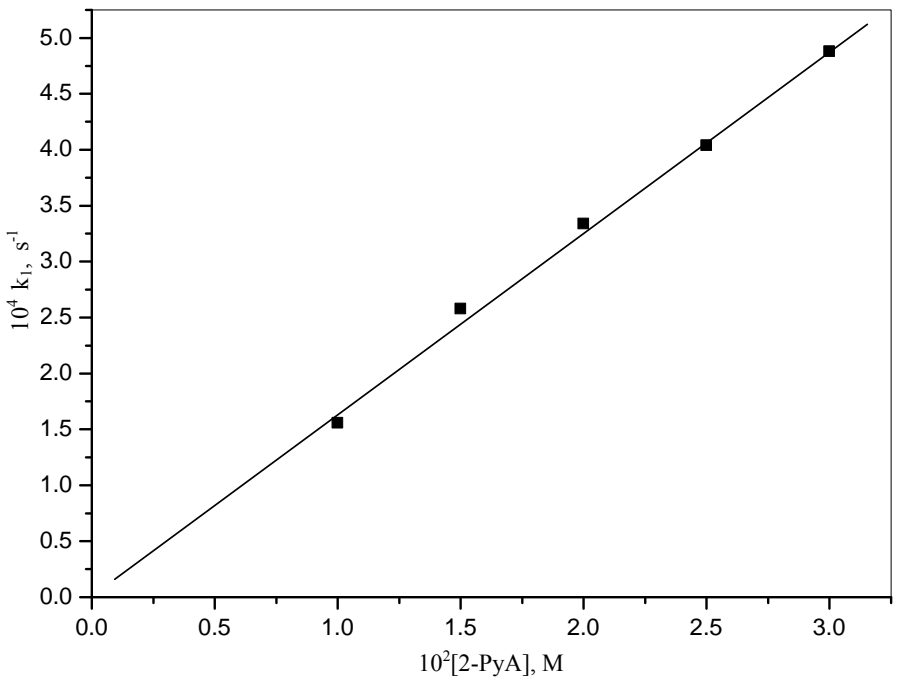

Figure 2. Direct plot of pyridine-2-aldehyde for the oxidation of pyridine-2-aldehyde by BIFC

\section{Effect of acidity}

The reaction is catalyzed by hydrogen ions (Table 1). The acid-catalysis may well be attributed to a protonation of BIFC to give a stronger oxidant and electrophile.

$$
\mathrm{O}_{2} \mathrm{CrFO}^{-} \mathrm{BIH}^{+}+\mathrm{H}^{+} \rightleftharpoons(\mathrm{OH}) \mathrm{OCrFO}^{-} \mathrm{BIH}^{+}
$$

The formation of a protonated $\mathrm{Cr}(\mathrm{VI})$ species has earlier been postulated in the reactions of structurally similar $\mathrm{PCC}^{31}$ and $\mathrm{PFC}^{32}$.

\section{Induced polymerization of acrylonitrile}

The possibility of radical formation and its involvement in the reaction has been ruled out as the addition of acrylonitrile in the reaction mixture developed no turbidity and hence the reaction rates was not affected even the [acrylonitrile] was at $1.0 \times 10^{-3}$ to $5.0 \times 10^{-3} \mathrm{~mol} \mathrm{dm}^{-3}$ (Table 2). Thus, a one electron oxidation giving rise to free radicals is unlikely.

\section{Effect of varying ionic strength of reaction rate}

The effect of ionic strength was studied by varying the $\mathrm{NaClO}_{4}$ concentration in the reaction medium. The ionic strength of the reaction medium was varied from $1.0 \times 10^{-3}$ to $5.0 \times 10^{-3}$ mol dm${ }^{-3}$ and keeping all other reactant concentration as constant. It was found that the values of the rate constants at different ionic strength of the reaction medium has no significant effect on the reaction rate (Table 2).

\section{Effect of solvent polarity on reaction rate}

The oxidation of 2-PyA has been studied in the binary mixture of acetic acid and water as the solvent medium. For the oxidation of 2-PyA, the reaction rate increased remarkably with the increase in the proportion of acetic acid in the solvent medium. These results are presented in Table 3.

The effect from solvent composition on the reaction rate was studied by varying the concentration of acetic acid from $30 \%$ to $70 \%$. The pseudo-first-order rate constants were estimated for the oxidation of 2-PyA, with BIFC in the presence of perchloric acid at a constant 
ionic strength. The reaction rate is increases markedly with the increase in the proportion of acetic acid in the medium (Table 3). When the acid content increases in the medium, the acidity of the medium is increased whereas the dielectric constant of the medium is decreased. These two effects cause the rate of the oxidation to increase markedly. The enhancement of the reaction rate with an increase in the amount of acetic acid generally may be attributed to two factors, viz, (i) the increase in acidity occurring at constant $\left[\mathrm{H}^{+}\right]$, and (ii) the decrease in the dielectric constant with an increase in the acetic acid content.

Table 2. Effect of acrylonitrile (AN) and $\mathrm{NaClO}_{4}$ on the oxidation of pyridine-2-aldehyde by BIFC at $303 \mathrm{~K}$

\begin{tabular}{ccc}
\hline $10^{3}[\mathrm{AN}], \mathrm{mol} \mathrm{dm}^{-3}$ & $10^{3}\left[\mathrm{NaClO}_{4}\right], \mathrm{mol} \mathrm{dm}^{-3}$ & $10^{4}, k_{l}, \mathrm{~s}^{-1}$ \\
\hline 0.0 & 0.0 & 3.42 \\
1.0 & 0.0 & 3.36 \\
2.0 & 0.0 & 3.40 \\
3.0 & 0.0 & 3.44 \\
4.0 & 0.0 & 3.37 \\
5.0 & 0.0 & 3.33 \\
0.0 & 1.0 & 3.47 \\
0.0 & 2.0 & 3.49 \\
0.0 & 3.0 & 3.36 \\
0.0 & 4.0 & 3.39 \\
0.0 & 5.0 & 3.40 \\
\hline
\end{tabular}

$10^{2}[2-\mathrm{PyA}]=2.0 \mathrm{~mol} \mathrm{dm} ; 10^{3}[\mathrm{BIFC}]=1.0 \mathrm{~mol} \mathrm{dm}^{-3} ; 10\left[\mathrm{H}^{+}\right]=3.2 \mathrm{~mol} \mathrm{dm}^{-3}$, Solvent composition $=$ $50 \% \mathrm{AcOH}-50 \% \mathrm{H}_{2} \mathrm{O}(\mathrm{v} / \mathrm{v})$

Table 3. Pseudo first-order rate constants for the oxidation of pyridine-2-aldehyde by BIFC at various percentage of acetic acid-water medium at various temperatures

\begin{tabular}{llllll}
\hline \multirow{2}{*}{$\begin{array}{c}\text { AcOH } \\
\mathrm{H}_{2} \mathrm{O}, v / v\end{array}$} & Dielectric & \multicolumn{4}{c}{$\mathrm{I}^{4} k_{l} \mathrm{~s}^{-1}$} \\
\cline { 3 - 6 } & constant & $298 \mathrm{~K}$ & $303 \mathrm{~K}$ & $308 \mathrm{~K}$ & $313 \mathrm{~K}$ \\
\hline $30-70$ & 72.0 & 1.66 & 2.40 & 3.40 & 4.90 \\
$40-60$ & 63.3 & 1.90 & 2.86 & 4.28 & 5.78 \\
$50-50$ & 56.0 & 2.28 & 3.34 & 4.76 & 6.84 \\
$60-40$ & 45.5 & 2.84 & 4.22 & 6.08 & 8.32 \\
$70-30$ & 38.5 & 3.44 & 5.02 & 7.42 & 10.88 \\
\hline $10^{2}[2-\mathrm{PyA}]=2.0 \mathrm{~mol} \mathrm{dm}^{-} ; 10^{3}[\mathrm{BIFC}]=1.0 \mathrm{~mol} \mathrm{dm}^{-3} ; 10\left[\mathrm{H}^{+}\right]=3.2 \mathrm{~mol} \mathrm{dm}^{-3}$
\end{tabular}

The plot of $\log k_{l}$ versus $1 / \mathrm{D}$ (dielectric constant) is linear with positive slope suggesting the presence of either dipole-dipole or ion-dipole type of interaction between the oxidant and the substrate ${ }^{33,34}$ (Figure 3). Plot of $\log k_{l}$ versus $(\mathrm{D}-1) /(2 \mathrm{D}+1)$ is a curvature indicating the absence of dipole - dipole interaction in the rate determining step.

Amis $(1967)^{35}$ holds the view that in an ion-dipole reaction involving a positive ionic reactant, the rate would decrease with increasing dielectric constant of the medium and if the reactant were to be a negatively charged ion, the rate would increase with the increasing dielectric constant. In this case there is a possibility of a positive ionic reactant, as the rate decreases with the increasing dielectric constant of the medium ${ }^{35}$. Due to the polar nature of the solvent, transition state is stabilized, i.e., the polar solvent molecules surround the transition state and result in less disproportion. 


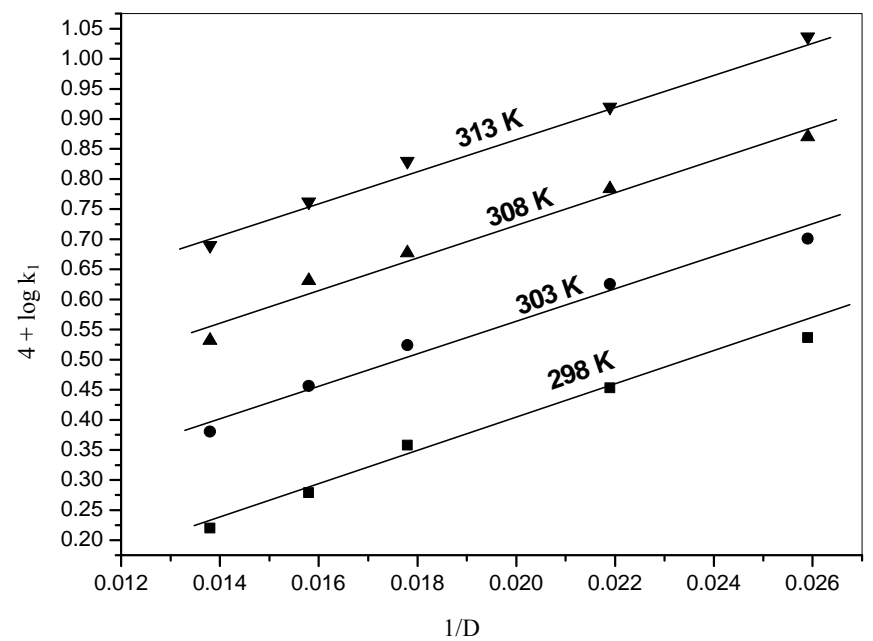

Figure 3. Plot of $1 / \mathrm{D}$ against $\log k_{\text {obs }}$ showing effect of solvent polarity for the oxidation of pyridine-2-aldehyde by BIFC at four different temperatures

\section{Thermodynamic parameters}

The kinetics of oxidation of 2-PyA was studied at four different temperatures viz., 298, 303, 308 and $313 \mathrm{~K}$. The second order rate constants were calculated (Table 4). The Arrhenius plot of $\log k_{2}$ versus $1 / \mathrm{T}$ is found to be linear. The enthalpy of activation, entropy of activation and free energy of activation were calculated from $k_{2}$ at 298, 303, 308 and $313 \mathrm{~K}$ using the Eyring relationship by the method of least square and presented in Table 4 . The entropy of activation is negative for 2-PyA.

Table 4. Second order rate constants and activation parameters for the oxidation of pyridine2-aldehyde by BIFC at various percentage of acetic acid-water medium

\begin{tabular}{|c|c|c|c|c|c|c|c|c|}
\hline \multirow{2}{*}{$\begin{array}{c}\% \mathrm{AcOH}- \\
\mathrm{H}_{2} \mathrm{O}, v / v\end{array}$} & \multicolumn{4}{|c|}{$10^{2} k_{2}, \mathrm{dm}^{3} \mathrm{~mol}^{-1} \mathrm{~s}^{-1}$} & \multirow{2}{*}{$\begin{array}{c}\mathrm{E}_{a}, \mathrm{~kJ} \\
\mathrm{~mol}^{-1}\end{array}$} & \multirow{2}{*}{$\begin{array}{c}-\Delta \mathrm{S}^{\#} \\
\mathrm{~J} \mathrm{~K}^{-1} \mathrm{~mol}^{-1}\end{array}$} & \multirow{2}{*}{$\begin{array}{c}\Delta \mathrm{H}^{\#}, \\
\mathrm{~kJ} \mathrm{~mol}^{-1}\end{array}$} & \multirow{2}{*}{$\begin{array}{c}\Delta \mathrm{G}^{\#}, \\
\mathrm{~kJ} \mathrm{~mol}^{-1} \\
\text { at } 303 \mathrm{~K}\end{array}$} \\
\hline & $298 \mathrm{~K}$ & $303 \mathrm{~K}$ & $308 \mathrm{~K}$ & $313 \mathrm{~K}$ & & & & \\
\hline $30-70$ & 0.83 & 1.20 & 1.70 & 2.45 & 54.18 & $113.02 \pm 0.6$ & $53.69 \pm 0.2$ & $87.94 \pm 0.4$ \\
\hline $40-60$ & 0.95 & 1.43 & 2.14 & 2.89 & 56.48 & $102.40 \pm$ & $53.80 \pm 1$ & $84.82 \pm 2.4$ \\
\hline $50-50$ & 1.14 & 1.67 & 2.38 & 3.42 & 54.94 & $105.66=$ & 53.46 & $85.47 \pm 0.8$ \\
\hline $60-40$ & 1.42 & 2.11 & 3.04 & 4.16 & 53.41 & $107.76 \pm 3.3$ & $51.50 \pm 1.1$ & $84.15 \pm 2.1$ \\
\hline $70-30$ & 1.72 & 2.51 & 3.71 & 5.44 & 57.32 & $096.44 \pm 1.8$ & $56.09 \pm 0.6$ & $85.31 \pm 1.2$ \\
\hline
\end{tabular}

\section{Isokinetic relationship}

The reaction is neither isoenthalpic nor isoentropic but complies with the compensation law also known as the isokinetic relationship.

$$
\Delta \mathrm{H}^{\#}=\Delta \mathrm{H}^{\mathrm{o}}+\beta \Delta \mathrm{S}^{\#}
$$

The isokinetic temperature $\beta$ is the temperature at which all the compounds of the series react equally fast. Also, at the isokinetic temperature, the variation of substituent has no influence on the free energy of activation. Exner suggested a method of testing the validity of isokinetic relationship ${ }^{36}$. The isokinetic relationship is tested by plotting the logarithms of rate constants at two different temperatures $\left(T_{2}>T_{1}\right)$ against each other according to Eq (4). 


$$
\log k\left(\text { at } \mathrm{T}_{2}\right)=\mathrm{a}+\mathrm{b} \log k\left(\text { at } \mathrm{T}_{1}\right)
$$

The linear relationship in Exner plots at $2+\log k_{2}(313 \mathrm{~K})$ and $2+\log k_{2}(303 \mathrm{~K})$ observed in the present study imply the validity of the isokinetic relationship ${ }^{37,38}$. Isokinetic temperature obtained is $705 \mathrm{~K}$. The linear isokinetic correlation implies that pyridine-2aldehyde is oxidized by the same mechanism in all the solvent compositions and the changes in the rate are governed by the changes in both the enthalpy and entropy of activation ${ }^{39}$.

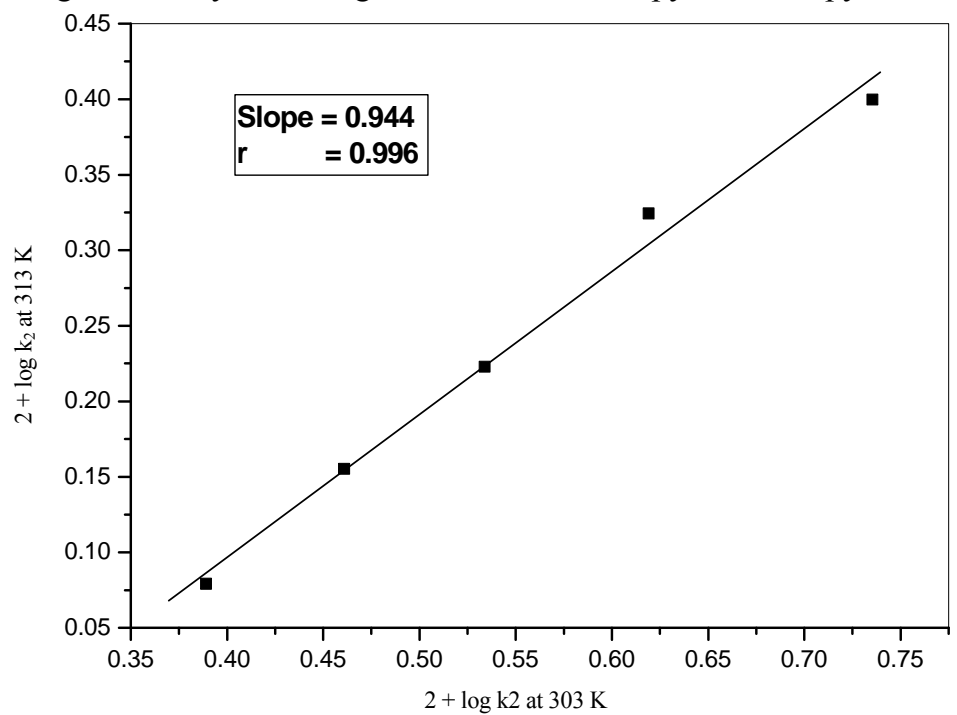

Figure 4. Exner's plot for the oxidation of pyridine-2-aldehyde by BIFC in various percentage of acetic acid-water mixture between $2+\log k_{2}$ (at $313 \mathrm{~K}$ ) and $2+\log k_{2}$ (at $303 \mathrm{~K}$ )

\section{Mechanism of oxidation}

A mechanism leading to the formation of the free radicals is unlikely in view of the failure to induce polymerization of acrylonitrile and no effect of the radical scavenger on the reaction rate. Positive slope of $\log k_{I}$ versus $1 / \mathrm{D}$ plot indicates that the reaction involves a cation-dipole type of interaction in the rate determining step. The linear isokinetic correlation implies that 2-PyA is oxidized by the same mechanism in all solvent compositions.

It has been shown that aldehyde oxidation reactions proceeded ${ }^{40-43}$ via the hydrated form. Hence, a mechanism involving a direct hydrogen-transfer reaction between a free aldehyde and BIFC was very unlikely.

The close resemblance in the structures of aldehyde hydrates and alcohols would favor similar pathways in their oxidation processes. The oxidation of alcohols had demonstrated the rate-determining decomposition of the protonated acid chromate ester ${ }^{44}$. In an analogous manner, the oxidation of aldehydes could be visualized as proceeding via the formation of a similar intermediate (an ester of the aldehyde hydrate). If the chromium was coordinated through the $-\mathrm{OH}$ group (of the aldehyde hydrate) in the cyclic transition state ${ }^{45,46}$ this would facilitate the formation of the chromate ester and enhance the ease of its oxidation to the corresponding carboxylic acid. Such a transition state envisaged the transfer of electrons towards the chromium, occurring by the formation of the carbon-hydrogen-oxygen bonds, as well as by the carbon-oxygen-chromium bonds. 
The slow step of the reaction involved the participation of the aldehyde hydrate, protonated BIFC and two electrons in a cyclic system. Removal of the hydrogen (on the carbon) was part of this step. The sequence of reactions for the oxidation of 2-PyA by $\mathrm{BIFCH}^{+}$, in acid medium (Scheme 1) showed that BIFC was converted to the protonated $\mathrm{BIFC}$ i.e., $\mathrm{BIFCH}^{+}$. The substrate $(\mathbf{A})$ was converted to the hydrated form $(\mathbf{H y})$, which reacted with $\mathrm{BIFCH}^{+}$, giving the monochromate ester intermediate $(\mathbf{E})$. The monochromate ester (E) underwent decomposition, in the rate determining step, to give the product picolinic acid, along with the $\mathrm{Cr}(\mathrm{IV})$ species.

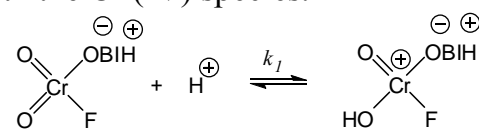<smiles>O=Cc1ccccn1</smiles>

(A)<smiles></smiles>

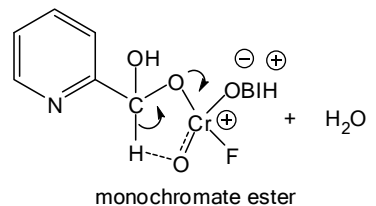

$k_{3} \downarrow$ slow

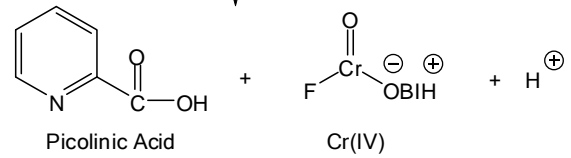

$$
\begin{array}{lll}
\mathrm{Cr}(\mathrm{IV})+\mathrm{Cr}(\mathrm{VI}) & \stackrel{\text { fast }}{\longrightarrow} & 2 \mathrm{Cr}(\mathrm{V}) \\
\mathrm{Cr}(\mathrm{V})+\text { Substrate } & \stackrel{\text { fast }}{\longrightarrow} & \text { Product }+\mathrm{Cr}(\mathrm{III})
\end{array}
$$

Scheme 1. Mechanism of oxidation of pyridine-2-aldehyde by BIFC

\section{Rate law}

The rate law has been derived as follows:

$$
-\mathrm{d}[\mathrm{BIFC}] / \mathrm{dt}=k_{3}[\mathrm{E}]=\mathrm{k}_{3}[\mathrm{Hy}]\left[\mathrm{BIFCH}^{+}\right]
$$

Where $[\mathrm{Hy}]=k_{2}[\mathrm{~A}]\left[\mathrm{H}_{2} \mathrm{O}\right]$ substituting the values of $\left[\mathrm{BIFCH}^{+}\right]$and $[\mathrm{Hy}]$ in the above Eq. 5 (taking the activity of water to be unity), we obtain $-\mathrm{d}[\mathrm{BIFC}] / \mathrm{dt}=$ $k_{1} k_{2} k_{3}[\mathrm{~A}][\mathrm{BIFC}]\left[\mathrm{H}^{+}\right]$indicating that reaction exhibited first-order dependence on the concentrations of each reactant (substrate, oxidant and acid)

\section{Conclusion}

The kinetics of oxidation of 2-PyA has been investigated in aqueous acetic acid medium in the presence of perchloric acid by spectrophotometrically at $303 \mathrm{~K}$. The oxidation of 2PyA by BIFC is first order each with respect to the $[2-\mathrm{PyA}],[\mathrm{BIFC}]$ and $\left[\mathrm{H}^{+}\right]$. The oxidation is 
catalysed by perchloric acid. The lowering of dielectric constant of reaction medium increases the reaction rate significantly. The reaction does not show the polymerization, which indicates the absence of free radical intermediate in the oxidation.

\section{References}

1. Hiran B L, Khuntwal A, Malkani R K and Singh D, Arab J Chem., 2011; DOI:10.1016/j.arabjc.2011.05.017

2. Zhang H K, Zhang X, Mao B Z, Li Q and He Z H, Cell Res., 2004, 14, 27-33; DOI:10.1038/sj.cr.7290199

3. Agarwal S, Chowdhury K and Banerji K K, J Org Chem., 1991, 56(17), 51115113; DOI:10.1021/jo00017a023

4. Krishnasamy K, Devanathan D and Dharmaraja J, Trans Met Chem., 2007, 32(7), 922-926; DOI:10.1007/s11243-007-0250-2

5. Pandurangan A and Murugesan V, React Kinet Catal Lett., 1995, 54(1), 173-180; DOI:10.1007/BF02071196

6. Asghar B H, Mansoor S S and Malik V S, Eur Chem Bull., 2013, 2(8), 538-544.

7. Mathiyalagan N and Sridharan R, Indian J Chem., 2005, 44A, 2044-2047.

8. Mansoor S S and Shafi S S, J Chem., 2009, 6(S1), S522-S528;

DOI:10.1155/2009/520170

9. Fathimajeyanthi G, Vijayakumar G and Elango K P, J Serb Chem Soc., 2002, 67, 803-811.

10. Gangwani H, Sharma P K, and Banerji K K, Int J Chem Kinet., 2000, 32(10), 615-622; DOI:10.1002/1097-4601(2000)32:10<615::AID-KIN3>3.0.CO;2-6

11. Chaubey G S, Das S and Mahanti M K, Heterocyclic Commun., 2002, 8(5), 497-500; DOI:10.1515/hc.2002.8.5.497

12. Chaubey G S, Das S and Mahanti M K, Bull Chem Soc Japan., 2002, 75(10), 22152220; DOI:10.1246/bcsj.75.2215

13. Chaubey G S, Bansie K and Mahendra K M, J Phy Org Chem., 2004, 17(1), 83-87; DOI:10.1002/poc.698

14. Radhasyam P and Puma R M, J Indian Chem Soc., 2006, 83, 491-494.

15. Saunte H, Chaubey G S and Mahanti M K, Croat Chem Acta., 2010, 83(3), 291-298.

16. Kumar V S, Rukmanganthan M and Ramkumar B, Asian J Chem., 2011, 23, 925-926.

17. Wiberg W B, Oxidation in Organic Chemisry, 1965, Academic Press, New York.

18. Harit H, Hiran B L, Joshi S N, Chem Sci Trans., 2015, 4(1), 49-58;

DOI:10.7598/cst2015.955

19. Das A and Mohanty P, Chem Sci Trans., 2014, 3(1), 1-10; DOI:10.7598/cst2014.278

20. Patwari S B, Khansole S V and Vibhute Y B, J Iran Chem Soc., 2009, 6(2), 399404; DOI:10.1007/BF03245850

21. Mansoor S S and Shafi S S, J Mole Liq., 2010, 155(2-3), 85-90;

DOI:10.1016/j.molliq.2010.05.012

22. Mansoor S S and Asghar B H, J Indian Chem Soc., 2013, 90, 1395-1401.

23. Alhaji N M I, Shajahan A and Ayyadurai G K, Chem Sci Trans., 2013, 2(2), 429434; DOI: $10.7598 /$ cst2013.376

24. Mansoor S S, Asghar B H and Malik V S, Arab J Chem., 2014; DOI:10.1016/j.arabjc.2014.10.047

25. Sivamurugan V, Rajkumar G A, Arabindoo B and Murugesan V, Indian J Chem., 2005, 44A, 144-147.

26. Dharmaraja J, Krishnasamy K and Shanmugam M, J Chem., 2008, 5(4), 754-760; DOI: $10.1155 / 2008 / 426508$ 
27. Mansoor S S, Asian J Chem., 2010, 22, 7591-7600.

28. Mansoor S S, Shafi S S and Ahmed S Z, Arab J Chem., 2011; DOI:10.1016/j.arabjc.2011.06.026

29. Mansoor S S and Shafi S S, Arab J Chem., 2014, 7(2), 171-176; DOI:10.1016/j.arabjc.2010.10.020

30. Asghar B H, Mansoor S S, Hussain A M, Malik V S, Aswin K and Sudhan S P N, Arab J Chem., 2013; DOI:10.1016/j.arabjc.2013.07.043

31. Sharma V, Sharma P K and Banerji K K, J Indian Chem Soc., 1997, 74, 607-609.

32. Sharma V, Sharma P K and Banerji K K, J Chem Research (S), 1996, 290-291.

33. Scatchard G J, Chem Phys., 1932, 10(2-3), 229-233; DOI:10.1016/0301-0104(75)87038-8

34. Scatchard G J, Chem Phys., 1939, 7, 657

35. Amis E S, Solvent Effects on Reaction Rates and Mechanisms. Academic Press, New York, 1967, 42.

36. Bhuvaseshwari D S and Elango K P, Int J Chem Kinet., 2007, 39(12), 657-663; DOI:10.1002/kin.20275

37. Exner O, Nature, 1964, 201, 488-490; DOI:10.1038/201488b0

38. Exner O, Streitwiser J R and Talt R W, Progress in Physical Organic Chemistry, John Wiley, New York, 1973, 41.

39. Leffler J F and Grunwald E, Rates and Equilibrium of Organic Reactions, Wiley, New York, 1963.

40. Jain A L and Banerji K K, J Chem Res (M), 1983, 678.

41. Banerji K K, Tetrahedron, 1987, 43, 5949-5954; DOI:10.1016/S0040-4020(01)87800-5

42. Sharma V K, Sharma K and Mishra N, Oxid Commun., 1993, 16, 33-39.

43. Medien H A A, Z Naturforsch., 2003, 58b, 1201-1205.

44. Rocek J, Westheimer F H, Eschenmoser A, Moldovanyi L and Schreiber J, Helv Chim Acta., 1962, 45(7), 2554-2567; DOI:10.1002/hlca.19620450725

45. Klanning U, Acta Chem Scand., 1958, 12, 576-577;

DOI:10.3891/acta.chem.scand.12-0576

46. Swain C G, Bader R F W, Estene R M and Griffin R N, J Am Chem Soc., 1961, 83(8), 1951-1955; DOI:10.1021/ja01469a040 